Check for updates

Cite this: RSC Adv., 2017, 7, 36335

\title{
Anti-microbial activity of chrysomycin A produced by Streptomyces sp. against Mycobacterium tuberculosis $\dagger$
}

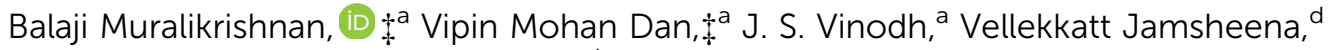
Ranjit Ramachandran, ${ }^{a}$ Sabu Thomas, ${ }^{b}$ Syed G. Dastager, ${ }^{e}$ K. Santhosh Kumar, ${ }^{c}$ Ravi Shankar Lankalapalli ${ }^{d}$ and Ramakrishnan Ajay Kumar ${ }^{\star a}$

Limited efficacy of the BCG (Bacillus Calmette-Guérin) vaccine against adult tuberculosis and the emergence of resistance to existing anti-tuberculosis drugs compel discovery of novel antibiotics against Mycobacterium tuberculosis. Actinomycetes are still an attractive platform for the discovery of new antimicrobials, especially from untapped natural hotspots, despite the belief that they are an exhausted resource after repeated re-discoveries. Herein we report the isolation and identification of chrysomycin A from an actinomycete isolated from a coastal area in Kerala. We show for the first time that it has antimycobacterial activity. It was found to be bactericidal to planktonic and intracellular M. tuberculosis with an MIC of $3.125 \mu \mathrm{g} \mathrm{mL}^{-1}$; it is non-hemolytic and has negligible cytotoxicity. The actinomycete that produces chrysomycin A was found to be a Streptomyces sp. through 16S rRNA gene sequencing.

Received 17th May 2017

Accepted 4th July 2017

DOI: $10.1039 / \mathrm{c} 7 \mathrm{ra05576e}$

rsc.li/rsc-advances
Actinomycetes have provided us with different classes of antibiotics that play a critical role in treating infectious diseases. ${ }^{8}$ They are the source of more than $45 \%$ of all known antibiotics and $90 \%$ of usable antibiotics available in the market. ${ }^{9,10}$ This is mainly due to their capacity to produce versatile bioactive secondary metabolites through their resourceful biosynthetic gene clusters. ${ }^{11}$ We hypothesized that ecological biodiversity hotspots such as coastal areas and tropical forests could harbour new strains of actinomycetes from which novel anti-mycobacterials could be isolated.

In this study, we screened culture filtrates of four hundred actinomycetes isolated from coastal areas and Western Ghats of Kerala, India. Ethyl acetate extract of a Streptomyces sp. OA161, was found to inhibit virulent laboratory strain MTB H37Rv. The active principle was purified, subjected to structural characterization and identified as chrysomycin A. This is the first report that chrysomycin A has anti-MTB activity. It was found to be non-cytotoxic to myoblast and epithelial cells and did not lyse red blood cells.

\footnotetext{
${ }^{a}$ Mycobacterium Research Laboratory, Rajiv Gandhi Centre for Biotechnology, Trivandrum, Kerala, India. E-mail: rakumar@rgcb.res.in

${ }^{b}$ Cholera and Biofilm Research Laboratory, Rajiv Gandhi Centre for Biotechnology, Trivandrum, Kerala, India

${ }^{c}$ Chemical and Environmental Biology, Rajiv Gandhi Centre for Biotechnology, Trivandrum, Kerala, India

${ }^{d}$ Chemical Sciences and Technology Division, National Institute for Interdisciplinary Science and Technology, CSIR, Trivandrum, Kerala, India

${ }^{e}$ NCIM Resource Centre, CSIR-National Chemical Laboratory, Pune, India

$\dagger$ Electronic supplementary information (ESI) available: Spectroscopic data and other relevant information for chrysomycin A; extract activity, bioautography and phylogenetic tree supportive data are given here. See DOI: 10.1039/c7ra05576e \$ These authors contributed equally.
}

\section{Results and discussion}

Screening of culture filtrate extracts for antimicrobial activity

Among four hundred isolates of actinomycetes screened for their antimicrobial activity, ethyl acetate extract of the culture filtrate of the isolate OA161 was found to inhibit the growth of MTB in vitro (ESI Data $1 \dagger$ ). The antimicrobial activity assay was extended to a panel of seven more microbes and the results revealed that it inhibited growth of Gram-positive bacteria but not of Gram-negative bacteria (Table 1). Based on the results, 
M. smegmatis was used as a surrogate organism to identify the active principle in the extract as the assay using MTB at every step of activity-guided separation was laborious and timeconsuming. The ethyl acetate extract was fractionated using thin layer chromatography and subsequent bioautography with M. smegmatis revealed an inhibitory zone and the spot was named AMF (antimycobacterial fraction) (ESI Data $2 \dagger$ ). Subsequently, the anti-MTB activity of AMF was confirmed by resazurin microtitre assay (REMA).

\section{Identification of the active principle}

Separation of AMF using HPLC revealed two prominent peaks with retention times 26.4 minutes (compound 2) and 28.7 minutes (compound 1, ESI Data $3 \dagger$ ). While the molecule eluted at 26.4 minutes had negligible activity, the one that eluted at 28.7 minutes had strong anti-MTB activity. The active principle was subjected to structural characterization by extensive NMR analysis which helped in identification of compound $\mathbf{1}$ as chrysomycin A (Fig. 1) which was further confirmed by comparison of the NMR data with that in the published literature ${ }^{12-15}$ (ESI Data 4-6†). The AMF, yellow solid (18 $\mathrm{mg}$ ) after separation through HPLC yielded compound 1 (2.5 $\mathrm{mg}$ ) and compound 2 (9.5 mg), respectively.

\section{Antimycobacterial activity of chrysomycin A}

Chrysomycin A was tested for antimycobacterial activity against MTB by REMA. Planktonic MTB was inhibited by the molecule at an MIC of $3.125 \mu \mathrm{g} \mathrm{mL} \mathrm{m}^{-1}$ and the same MIC was observed with commercially available chrysomycin A (Abcam). The MIC we observed is therefore better than that of two firstline anti-TB drugs, ethambutol $\left(4 \mu \mathrm{g} \mathrm{mL}^{-1}\right)$ and pyrazinamide $\left(16 \mu \mathrm{g} \mathrm{mL}{ }^{-1}\right) .{ }^{16,17}$

Time-course experiment with free-living MTB revealed that the activity is bactericidal in nature as the CFUs were reduced by three $\log _{10}$ folds at MIC and more at higher concentrations. In fact, no colonies were found when bacteria were treated with chrysomycin A $\left(3.125 \mu \mathrm{g} \mathrm{mL}^{-1}\right)$ for 24 hours. At this concentration the bactericidal activity was comparable to that of rifampicin $\left(1 \mu \mathrm{g} \mathrm{mL}{ }^{-1}\right)$. Above $7.8 \mu \mathrm{g} \mathrm{mL}^{-1}$, which is the $\mathrm{IC}_{50}$ for THP-1-derived macrophages, no colonies were found at any<smiles></smiles>

Fig. 1 Structure of chrysomycin A.

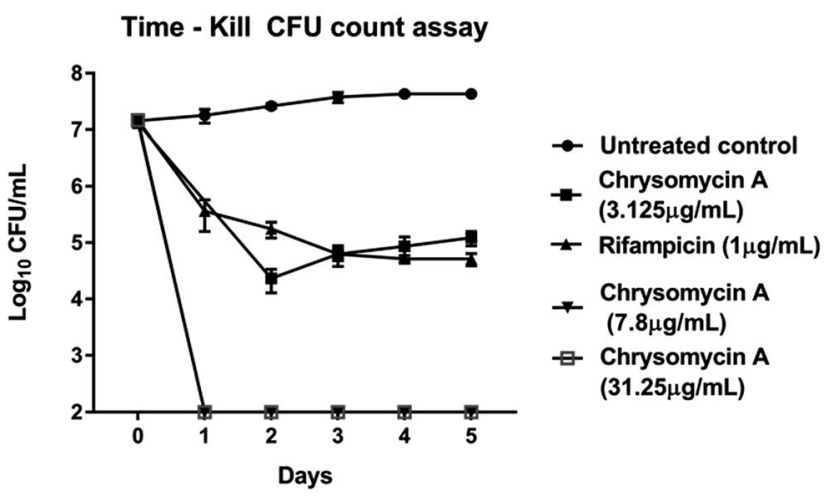

Fig. 2 Kinetics of bactericidal activity of chrysomycin A on planktonic MTB. Data presented is mean \pm SD of three independent experiments.

time point checked on planktonic MTB (Fig. 2). Interestingly the compound was also found to be inhibitory to intracellular MTB at the same concentration (Fig. 3). The antimycobacterial activity of chrysomycin $\mathrm{A}$ is comparable to that of rifampicin $\left(1 \mu \mathrm{g} \mathrm{mL}{ }^{-1}\right)$ as the CFU data suggested. This is the first report that chrysomycin A has anti-MTB activity against planktonic as well as intracellular MTB.

Chrysomycin A was found to inhibit M. smegmatis and $B$. subtilis but not Gram negative bacteria by Strelitz et al. ${ }^{\mathbf{1 4}}$ Our study also showed that it has the ability to inhibit $M$. smegmatis at almost the same concentration $\left(0.6 \mu \mathrm{g} \mathrm{mL} \mathrm{mL}^{-1}\right)$. In addition, it is inhibitory to drug resistant strains of Staphylococcus aureus

Table 1 Antimicrobial activity of ethyl acetate extract and chrysomycin A by REMA. Data presented is mean \pm SD of three independent experiments. MIC with no \pm SD represents consistent results with the same value ${ }^{a}$

\begin{tabular}{|c|c|c|}
\hline Bacteria tested & $\begin{array}{l}\text { Antimicrobial activity of the } \\
\text { ethyl acetate extract }\end{array}$ & $\begin{array}{l}\text { MIC }\left(\mu \mathrm{g} \mathrm{mL} L^{-1}\right) \\
\text { of chrysomycin A }\end{array}$ \\
\hline Mycobacterium tuberculosis $\mathrm{H} 37 \mathrm{Rv}$ & + & $3.125 \pm 0.5$ \\
\hline Staphylococcus aureus ATCC 25923 & + & 0.5 \\
\hline MRSA (methicillin resistant Staphylococcus aureus) & + & 2 \\
\hline VRE (vancomycin resistant Enterococcus faecalis) & + & 0.5 \\
\hline Vibrio cholerae $\mathrm{N} 16961$ & - & $>50$ \\
\hline
\end{tabular}


Intracellular survival of MTB after $24 \mathrm{hrs}$ of treatment with Chrysomycin A

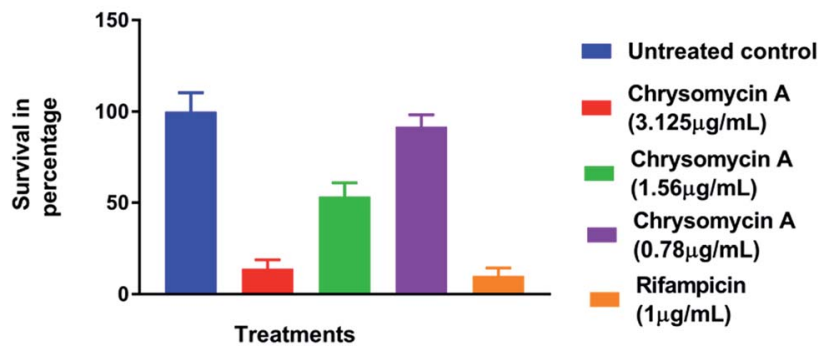

Fig. 3 Survival of intracellular MTB in the presence of chrysomycin A. Data represented is mean \pm SD of three independent experiments.

and Enterococcus faecalis. It was active against MRSA (methicillin resistant Staphylococcus aureus) and VRE (vancomycin resistant Enterococcus faecalis) in vitro with an MIC of $2 \mu \mathrm{g} \mathrm{mL} \mathrm{m}^{-1}$ and $0.5 \mu \mathrm{g} \mathrm{mL}{ }^{-1}$, respectively. It was not inhibitory to Gram negative bacteria tested (E. coli, Pseudomonas aeruginosa and Vibrio cholerae). Interestingly, this molecule has also been reported to cause DNA damage and apoptosis in leukemic cell line HL60. ${ }^{13}$ Our study therefore highlights the need for repurposing existing and abandoned drugs as recommended by Boguski et al. ${ }^{18}$

\section{Chrysomycin A is non-hemolytic}

Human erythrocytes were unharmed even at a concentration ten times the MIC against MTB whereas 1\% SDS resulted in complete lysis (Fig. 4). This is another attractive characteristic of an ideal antimicrobial lead molecule. MTT assay revealed that cell lines L6 and SW480 were also unaffected even at $31.25 \mu \mathrm{g} \mathrm{mL}{ }^{-1}$ while THP-1-derived macrophages had an $\mathrm{IC}_{50}$ of $7.8 \mu \mathrm{g} \mathrm{mL} \mathrm{mL}^{-1}$, but largely remained unharmed at the MIC (3.125 $\mu \mathrm{g} \mathrm{mL}^{-1}$ ) (Fig. 5).

The high cytotoxicity of chrysomycin A on THP-1 cells in comparison with the others was rather puzzling, however we presume that this is perhaps due to the fact that THP-1 cells are derived from human leukemia, and chrysomycin A has been reported to possess anti-leukemic activity. ${ }^{13}$ Interestingly, when tested on mice, chrysomycin A was not lethal even at $400 \mathrm{mg}$ $\mathrm{kg}^{-1}$ dose and it was, on the other hand, found to increase the life span of the tumour-induced animals. ${ }^{15}$

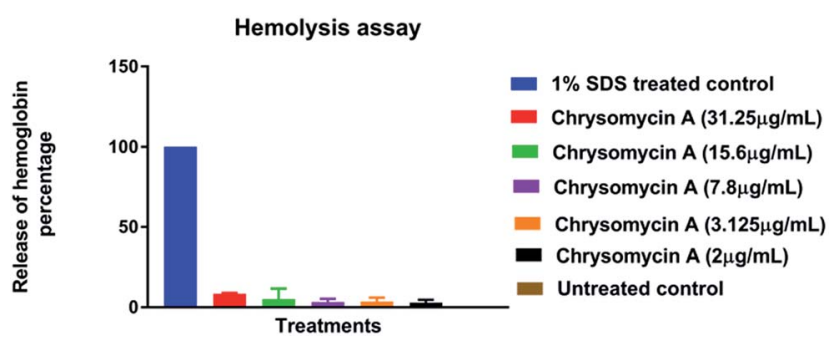

Fig. 4 Hemolysis assay: chrysomycin A is non-hemolytic even at ten times the MIC $\left(31.25 \mu \mathrm{g} \mathrm{mL}^{-1}\right)$. Data presented is mean \pm SD of three independent experiments.

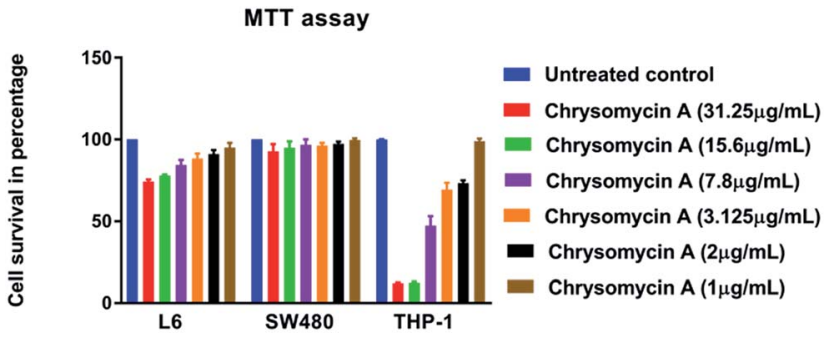

Fig. 5 MTT assay: cytotoxicity of chrysomycin A was analyzed on cell lines up to ten times the MIC $\left(31.25 \mu \mathrm{g} \mathrm{mL}{ }^{-1}\right)$. Little or negligible toxicity was found against L6 (rat myoblast cell line) and SW480 (epithelial cell line from colon). It was relatively more toxic against THP-1-derived macrophages. Data presented is mean \pm SD of three independent experiments.

\section{Isolate that produces chrysomycin A is a Streptomyces $\mathbf{s p .}$} OA161

The partial 16S rRNA gene sequence of our isolate was submitted to GenBank, NCBI (accession number, KX364040). It is 1410 bp in length and $99.07 \%$ similar to that of Streptomyces smyrnaeus. A phylogenetic tree was generated using neighbor joining method $^{19}$ using MEGA 7 software and the isolate forms a separate clade that is characteristic of a separate species (ESI Data $7 \dagger$ ).

\section{Experimental}

General procedures, strains, cell lines and chemicals

Mycobacterium tuberculosis $\mathrm{H} 37 \mathrm{Rv}$ was grown in Middlebrook 7H9 medium (Difco) supplemented with 10\% OADC (Difco). Other bacteria used in this study are Mycobacterium smegmatis mc $^{2} 155$, Staphylococcus aureus ATCC 25953, MRSA (methicillin resistant Staphylococcus aureus) clinical strain C10, VRE (vancomycin resistant Enterococcus faecalis) clinical strain E8, E. coli ATCC 25922, Pseudomonas aeruginosa clinical strain R8 and Vibrio cholera N16961 and were grown in Luria Bertani broth (HiMedia, Mumbai). The clinical strains were a kind gift from the Department of Microbiology, Government Medical College, Trivandrum. Nalidixic acid, nystatin, gentamycin, phorbol 12-myristate 13-acetate (PMA) and resazurin were purchased from Sigma; Cell lines L6 (rat myoblast), SW480 (epithelial cell from colon) and THP-1 (Human monocytes) were obtained from National Centre for Cell Science, Pune, India. Cell lines were maintained in RPMI1640 (Sigma) or DMEM (Dulbecco's Modified Eagle's Medium, Gibco) with 10\% FBS (Gibco). The extracts and antibiotics were prepared in DMSO and the final concentration of DMSO used in the assays was $2 \%$ whenever used for antimicrobial activity.

\section{Isolation of actinomycetes}

About 10 grams of soil samples were collected in sterile bags from the sub-soil of different ecological niches and were dried under shade. This was suspended in sterile water $\left(1 \mathrm{gm} \mathrm{mL}^{-1}\right)$, serially diluted and plated on selective solid growth media (starch casein agar/actinomycetes isolation agar/ISP-2/ISP-7) with or without nalidixic acid $\left(100 \mu \mathrm{g} \mathrm{mL}^{-1}\right)$ and nystatin (50 $\mu \mathrm{g} \mathrm{mL}^{-1}$ ) and incubated at $25{ }^{\circ} \mathrm{C}$ for 2 weeks. Once chalky colonies appeared, they were further purified on ISP-2 agar. The 
pure colonies were stored in the form of stabs or as glycerol stocks at $4{ }^{\circ} \mathrm{C}$ and $-20{ }^{\circ} \mathrm{C}$, respectively.

\section{Purification of anti-mycobacterial principle}

Single colony of the actinomycete isolate (OA161) was inoculated in modified ISP-2 medium $(50 \mathrm{~mL})$ and grown at $30^{\circ} \mathrm{C}$ on a shaker incubator $(250 \mathrm{rpm})$. Two glass marbles were introduced into the medium to prevent clumping of the culture. After 6 days, the culture filtrate was prepared by centrifugation of the culture at $6000 \mathrm{rpm}$ for 15 minutes at room temperature followed by filtration through Whatman 3 filter paper, and passing through $0.2 \mu \mathrm{m}$ membrane filter. The supernatant was frozen at $-80{ }^{\circ} \mathrm{C}$ before lyophilization. The lyophilized powder of the culture filtrate was extracted with ethyl acetate, chloroform, acetone and methanol and these extracts were concentrated under vacuum and used in the antimicrobial assay.

\section{Resazurin microtitre assay (REMA)}

The assay was carried as described by Martin et al. ${ }^{20}$ Briefly, MTB H37Rv and M. smegmatis were grown in Middlebrook 7H9 medium, turbidity of the culture was adjusted to McFarland standard 1 and further diluted 20 times. For other test strains, Luria Bertani broth (HiMedia) was used for growth. One hundred microlitre of the diluted culture was transferred to the wells of a 96 well microtitre plate (Thermo Fisher). The extracts and purified active principle were dissolved in DMSO and added to a final concentrations of $200 \mu \mathrm{g} \mathrm{mL} L^{-1}$ to $0.78 \mu \mathrm{g} \mathrm{mL} L^{-1}$ in a final volume of $200 \mu \mathrm{L}$ per well. The plates were incubated for 7 days, with negative (no drug) and positive controls (rifampicin and ciprofloxacin at $1 \mu \mathrm{g} \mathrm{mL} \mathrm{m}^{-1}$ ). MIC was determined after the addition of Resazurin ( $0.25 \%$ solution in water) on the $8^{\text {th }}$ day which either remains blue or changes to pink (after 24 hours) based on the viability of the bacteria. Blue indicates that the bacteria are susceptible (inhibition), and pink indicates the bacteria are resistant to killing (viable) by the extract.

\section{Thin layer chromatography and bioautography}

Normal phase Silica gel $60 \mathrm{~F}_{254}$ aluminum TLC plates (Merck, India) were used to fractionate the ethyl acetate extract of the culture filtrate of the isolate. Hexane : Acetone $(1: 1)$ was used as the mobile phase. The TLC plate was allowed to develop in a sterile, saturated closed chamber for 35 minutes. The fractionated TLC plate was overlayed with Muller Hinton soft agar containing $S$. aureus or $M$. smegmatis. This was allowed to solidify and incubated for 24 hours (S. aureus) or 36 hours (M. smegmatis) at $37^{\circ} \mathrm{C}$. The active fraction was named AMF (antimycobacterial fraction) and this was subjected to HPLC.

\section{Purification and characterization of the active principle}

General procedures. Shimadzu HPLC instrument with C18phenomenex reverse phase column $(250 \times 21.2 \mathrm{~mm}, 5 \mu \mathrm{m})$ was used for purification of the extract using acetonitrile (ACN) and water. ${ }^{1} \mathrm{H}$ and ${ }^{13} \mathrm{C}$ NMR spectra were recorded at $500 \mathrm{MHz}$ and $125 \mathrm{MHz}$ on a Bruker DRX 500 NMR instrument (Bruker, Rheinstetten, Germany). Deuterated acetone $\left(\left(\mathrm{CD}_{3}\right)_{2} \mathrm{CO}\right)$ was used for recording the NMR spectrum, chemical shifts are given in parts per million (ppm), and coupling constants in Hz. HRESI-MS analysis was performed on a Thermo Scientific Exactive mass spectrometer with ions given in $\mathrm{m} / \mathrm{z}$.

Isolation and identification of the active principle. The AMF (yellow solid) was identified as a mixture of two closely related compounds by TLC and ${ }^{1} \mathrm{H}-\mathrm{NMR}$. The compound mixture was dissolved in acetonitrile ( $3 \mathrm{~mL}$ ) and then subjected to purification by reverse-phase preparative HPLC with a gradient program comprising of mobile phase system: solvent $A$ (water) and solvent B (ACN). The linear gradient started with $35 \%$ B at 0 min to $80 \% \mathrm{~B}$ for $30 \mathrm{~min}$, and $100 \% \mathrm{~B}$ up to 35 minutes at a flow rate of $7 \mathrm{~mL} \mathrm{~min}{ }^{-1}$, monitored at $254 \mathrm{~nm}$. Three major peaks were identified at a retention time of 26.4 minutes, 28.7 minutes, and 30.1 minutes (ESI Fig. $3 \dagger$ ). The compound eluted at 28.7 minutes was found to inhibit MTB H37Rv in vitro and therefore was subjected to characterization by ${ }^{1} \mathrm{H},{ }^{13} \mathrm{C}, 2 \mathrm{D}$ NMR and mass spectrometry.

Colony forming unit (CFU) count assay. McFarland standard 1 of mid-log phase MTB H37Rv culture was diluted 20 times and treated with chrysomycin $\mathrm{A}$ at varying concentrations (3.125-31.25 $\left.\mu \mathrm{g} \mathrm{mL} \mathrm{m}^{-1}\right)$ at $37^{\circ} \mathrm{C}$ for $6-48$ hours. Rifampicin $(1 \mu \mathrm{g}$ $\mathrm{mL}^{-1}$ ) served as positive control and $2 \%$ DMSO as negative control. All the treated and untreated cultures were diluted further and plated on $7 \mathrm{H} 10$ agar containing $0.1 \%$ casitone (Difco). The cfus were counted after 3 weeks.

Anti-mycobacterial activity on intracellular MTB. Twenty thousand THP-1 cells were seeded and were induced with PMA (20 $\mathrm{ng} \mathrm{mL} \mathrm{mL}^{-1}$ ) for 18-24 hours to differentiate them into macrophages. These cells were infected with MTB H37Rv at an MOI of $20: 1$. Four hours after infection, the external bacteria (which were not phagocytosed) were treated with gentamycin $\left(45 \mu \mathrm{g} \mathrm{mL}{ }^{-1}\right)$, and the cells were subsequently treated with chrysomycin $\mathrm{A}\left(3.125 \mu \mathrm{g} \mathrm{mL} \mathrm{m}^{-1}, 1.56 \mu \mathrm{g} \mathrm{mL} \mathrm{m}^{-1}\right.$ and $\left.0.78 \mu \mathrm{g} \mathrm{mL} \mathrm{m}^{-1}\right)$. Macrophages treated with rifampicin $\left(1 \mu \mathrm{g} \mathrm{mL}{ }^{-1}\right)$ were taken as positive control and untreated macrophages as negative control. These were incubated at $37{ }^{\circ} \mathrm{C}$ for 48 hours and lysed with distilled water. The lysate was plated on $7 \mathrm{H} 10$ agar containing $0.1 \%$ casitone (Difco) and the colonies were counted after 3-4 weeks of incubation at $37^{\circ} \mathrm{C}$.

MTT assay. The assay was carried out as described by van Meerloo et al. $^{21}$ Briefly, 10000 cells were seeded per well in a 96 well plate in triplicates. They were treated with chrysomycin A at different concentrations (1-31.25 $\left.\mu \mathrm{g} \mathrm{mL}^{-1}\right)$ and incubated for 48 hours at $37{ }^{\circ} \mathrm{C}$ in the presence of $5 \% \mathrm{CO}_{2}$. Twenty microlitre of MTT (3-(4,5-dimethylthiazole-2-yl)-2,5-diphenyl tetrazolium bromide) dye (5 $\mathrm{mg} \mathrm{mL}^{-1}$ ) was added to each well and after 4 hours, the reaction was terminated by adding $200 \mu \mathrm{L}$ of isopropanol and this dissolves the formazan crystals. This was read at $540 \mathrm{~nm}$ on an ELISA reader (Bio-Rad).

Hemolysis assay. The assay was carried out as described by Evans et al..$^{22}$ with minor modifications. Briefly, $10 \%(\mathrm{v} / \mathrm{v})$ fresh suspension of human erythrocytes in phosphate buffered saline (PBS, pH 7.2) was incubated with various concentrations of chrysomycin A $\left(2-31.25 \mu \mathrm{g} \mathrm{mL} \mathrm{m}^{-1}\right)$ at $37{ }^{\circ} \mathrm{C}$ for 1 hour. One percent SDS (w/v) in water served as positive control and PBS served as negative control. The suspensions were centrifuged 
$(3000 \times g)$ for 5 minutes at room temperature and the supernatant was read at $595 \mathrm{~nm}$ to measure the amount of hemoglobin released. Hemolysis was interpreted in percentage after calculating it from three individual experiments.

Sequencing of 16S rRNA and polyketide synthase II alpha subunit genes. Genomic DNA was isolated from the isolate OA161 as described by Lee et $a .^{23}$ The $16 \mathrm{~S}$ rRNA gene was amplified with universal primers (ESI Table $2 \dagger$ ). Fifty microlitre amplification reaction had $1 \mu \mathrm{L}$ template DNA (50-200 ng), $10 \mu \mathrm{L} 10 \times$ PCR buffer with $\mathrm{MgCl}_{2}$ (Sigma), $1 \mu \mathrm{L}$ of forward and reverse primer $(20 \mathrm{mM})$ each, $2 \mu \mathrm{L}$ dNTP mix ( $5 \mathrm{mM}$ ), $1 \mathrm{U}$ Taq DNA polymerase (Sigma) and $34 \mu \mathrm{L}$ sterile MilliQ water. The reaction conditions were: initial denaturation at $95{ }^{\circ} \mathrm{C}$ for 5 minutes, followed by 30 cycles of denaturation at $95{ }^{\circ} \mathrm{C}$ for 30 seconds, annealing at $54{ }^{\circ} \mathrm{C}$ for 30 seconds and extension at $72{ }^{\circ} \mathrm{C}$ for 45 seconds. A final extension was performed at $72{ }^{\circ} \mathrm{C}$ for 7 minutes. For polyketide synthase II alpha subunit gene, the amplification reaction conditions remained the same except that the annealing temperature was $62{ }^{\circ} \mathrm{C}$. The products were electrophoresed on a $1 \%$ agarose gel containing ethidium bromide and visualized under UV light. The PCR product was purified using GE Healthcare gel band purification kit and sequenced directly using a Taq BigDye Terminator Cycle Sequencing Kit in ABI automated DNA sequencer (Applied Biosystems). Both genes were sequenced with different forward and reverse sequencing primers to cross check the sequence. The sequences were compared with help of Ez-Taxon and BLAST database, respectively.

\section{Conclusion}

Chrysomycin A, isolated from a new species of Streptomyces, showed bactericidal activity against planktonic as well as intracellular MTB at an MIC of $3.125 \mu \mathrm{g} \mathrm{mL}{ }^{-1}$. This is the first report of chrysomycin A possessing anti-MTB activity.

\section{Conflicts of interest}

The authors declare that there are no conflicts of interest.

\section{Acknowledgements}

RAK and ST thank financial support from Open Source Drug Discovery (OSDD), Council of Scientific and Industrial Research (CSIR) (OSDD/HCP0001/12FYP/2012-123/Fin/2412), Government of India. BM thanks Council of Scientific and Industrial Research, Government of India, for research fellowship. VMD was supported by Fast Young Scientist Scheme (SERB:SB/FT/LS322/2012) of Department of Science and Technology, Government of India. VJS thanks OSDD-CSIR for fellowship. SGD thanks financial support from Council of Scientific and Industrial Research, Government of India.

\section{References}

1 W. H. Organization, Global tuberculosis report 2015, World Health Organization, 2015.
2 L. Brandt, J. F. Cunha, A. W. Olsen, B. Chilima, P. Hirsch, R. Appelberg and P. Andersen, Infect. Immun., 2002, 70, 672-678.

3 I. Gelmanova, S. Keshavjee, V. Golubchikova, V. Berezina, A. K. Strelis, G. V. Yanova, S. Atwood and M. Murray, Bull. W. H. O., 2007, 85, 703-711.

4 J. E. de Steenwinkel, T. Marian, G. J. de Knegt, H. A. Verbrugh, R. E. Aarnoutse, M. J. Boeree, M. A. den Bakker, D. van Soolingen and I. A. Bakker-Woudenberg, Antimicrob. Agents Chemother., 2012, 56, 4937-4944.

5 K. Dheda, T. Gumbo, N. R. Gandhi, M. Murray, G. Theron, Z. Udwadia, G. B. Migliori and R. Warren, Lancet Respir. Med., 2014, 2, 321-338.

6 N. R. Gandhi, P. Nunn, K. Dheda, H. S. Schaaf, M. Zignol, D. Van Soolingen, P. Jensen and J. Bayona, Lancet, 2010, 375, 1830-1843.

7 M. Klopper, R. M. Warren, C. Hayes, N. C. Gey van Pittius, E. M. Streicher, B. Muller, F. A. Sirgel, M. Chabula-Nxiweni, E. Hoosain and G. Coetzee, Emerging Infect. Dis., 2013, 19(3), 449-455.

8 A. Raja and P. Prabakarana, Am. J. Drug Discovery Dev., 2011, 1, 75-84.

9 J. Berdy, J. Antibiot., 2005, 58, 1-26.

10 G. B. Mahajan and L. Balachandran, Front. Biosci., Elite Ed., 2011, 4, 240-253.

11 M. Nett, H. Ikeda and B. S. Moore, Nat. Prod. Rep., 2009, 26, 1362-1384.

12 G. T. Carter, A. A. Fantini, J. C. James, D. B. Borders and R. J. White, J. Antibiot., 1985, 38, 242-248.

13 S. K. Jain, A. S. Pathania, R. Parshad, C. Raina, A. Ali, A. P. Gupta, M. Kushwaha, S. Aravinda, S. Bhushan, S. B. Bharate and R. A. Vishwakarma, RSC Adv., 2013, 3, 21046-21053.

14 F. Strelitz, H. Flon and I. N. Asheshov, J. Bacteriol., 1955, 69, 280-283.

15 U. Weiss, K. Yoshihira, R. Highet, R. J. White and T. T. Wei, J. Antibiot., 1982, 35, 1194-1201.

16 S. G. Franzblau, R. S. Witzig, J. C. McLaughlin, P. Torres, G. Madico, A. Hernandez, M. T. Degnan, M. B. Cook, V. K. Quenzer and R. M. Ferguson, J. Clin. Microbiol., 1998, 36, 362-366.

17 G. Jadaun, C. Agarwal, H. Sharma, Z. Ahmed, P. Upadhyay, J. Faujdar, A. K. Gupta, R. Das, P. Gupta and D. Chauhan, J. Antimicrob. Chemother., 2007, 60, 152-155.

18 M. S. Boguski, K. D. Mandl and V. P. Sukhatme, Science, 2009, 324, 1394-1395.

19 N. Saitou and M. Nei, Mol. Biol. Evol., 1987, 4, 406-425.

20 A. Martin, M. Camacho, F. Portaels and J. C. Palomino, Antimicrob. Agents Chemother., 2003, 47, 3616-3619.

21 J. van Meerloo, G. J. Kaspers and J. Cloos, Cancer cell culture: methods and protocols, 2011, pp. 237-245.

22 B. C. Evans, C. E. Nelson, S. Y. Shann, K. R. Beavers, A. J. Kim, H. Li, H. M. Nelson, T. D. Giorgio and C. L. Duvall, J. Visualized Exp., 2013, e50166.

23 Y. Lee, H. Kim, C. Liu and H. Lee, J. Microbiol. Methods, 2003, 52, 245-250. 